\title{
Laporan Budaya
}

\section{POPOKAN: TRADISI PERANG LUMPUR DI TRADISI DESA SENDANG, KECAMATAN BRINGIN, KABUPATEN SEMARANG}

\author{
Muh Hafidz \\ Uiversitas Islam Negeri Walisongo Semarang
}

\begin{abstract}
Initially the tradition of popokan is the original tradition of Sendang village. It is developed into a unique tradition in Semarang Regency. The tradition is not only limited to the tradition of mud war among villagers of Sendang Village, but also modified with various processions in the form of cleaning wells or water sources, tumpengan (food offering), carnival and popokan war. Popokan tradition is an expression of gratitude to God the Almighty as the Ruler of the Universe, in order to keep away from various disasters and calamities. This tradition is also an expression of artistic ability and creativity of citizens, especially after the Tourism Office of Semarang Regency manages it in order to preserve local wisdom from the tradition of the local ancestors.
\end{abstract}

Key words: popokan war tradition, Sendang Village, tumpengan, carnival, Semarang Regency

\section{Pendahuluan}

Sendang merupakan nama sebuah dusun (dukuh) sekaligus nama sebuah kelurahan yang berlokasi di Kecamatan Bringin, Kabupaten Semarang, Jawa Tengah. Desa ini berada di sebelah utara Kota Salatiga, kira-kira 12 kilometer dan Kota Salatiga, atau kira-kira 2 kilometer dari Kecamatan Bringin. Desa Sendang terdiri dari lima dusun, yakni Dusun Ngasinan, Dusun Sendang, Dusun Pondok, Dusun Kembangkerep, dan Dusun Digelan. Masing-masing dusun dipimpin oleh kepala dusun atau Kadus. Demikian hasil wawancara dengan Faizin, mantan kepala desa, Desa Sendang, Kecamatan Bringin.

Dusun Ngasinan secara geografis berada paling tinggi di antara dusun-dusun lainnya. Dusun ini berada di paling barat, didominasi lahan tanah kering di kanan kiri jalan dusun. Ada lahan pertanian di sebelah selatan dusun di jalan menuju Desa Lebak. Kemudian Dusun Sendang didominasi lahan pertanian padi yang berada di sebelah kanan kiri jalan dusun. Balai Desa Sendang juga berlokasi di Dusun Sendang ini, tepat di pinggir jalan raya Salatiga Bancak di ujung timur Dusun Sendang. Selanjutnya Dusun Pondok, di sebelah timur Dusun
Sendang, berlokasi di jalur Salatiga Bancak. Dusun ini juga didominasi lahan pertanian yang sangat subur. Sementara Dusun Digelan dan Kembangkerep berlokasi di sebelah selatan Dusun Pondok, di jalur menuju Desa Semowo, Kecamatan Pabelan. Demikian hasil pengamatan dan penulis di lokasi penelitian.

Mayoritas mata pencaharian warga Desa Sendang adalah pertanian, khususnya pertanian padi dan palawija. Lahan pertanian terlihat memanjang di kanan kiri jalan di sepanjang jalan Salatiga-Bancak. Bondo deso sebagai aset yang dimiliki desa sangat banyak. Sekali panen, hasil bengkok lurah kepala desa dapat mencapai 60 juta rupiah, demikian kata Faizin, mantan kepala desa. Di sekitar desa, sebelah utara dan selatan desa dikelilingi oleh lahan persawahan dan lahan tegalan, pertanian tanah kering. Sebagian warga bermata pencaharian sebagai tukang dan kuli bangunan, yang lajo ke Salatiga. Sebagian yang lain merantau ke luar kota untuk memperoleh penghasilan bagi kehidupan keluarganya.

Desa Sendang, pada awalnya sebagaimana desa-desa lainnya, tidak begitu dikenal di Salatiga atau di 
Kabupaten Semarang. Hampir semua warga Kecamatan Bringin sangat familiar dengan Salatiga disebabkan Salatiga merupakan kota terdekat yang dapat dicapai dalam waktu 30 menit. Di samping itu, Salatiga merupakan tempat untuk menjual hasil pertanian setiap harinya. Hasil pertanian misalnya pisang, daun singkong dibawa oleh pengepul dan didistribusikan di Kota Salatiga. Dengan demikian, Salatiga mempunyai ikatan emosional yang sangat kuat dengan warga desa di Kecamatan Bringin, demikian hasil observasi penulis. Di samping itu, mayoritas mereka memenuhi kebutuhan peralatan dan perabotan rumah tangga dari Salatiga.

Di Desa Sendang ini ada tradisi yang terkenal dengan nama popokan, dan dikenal pula dengan nama perang lumpur. Tradisi popokan sebenarnya merupakan sebuah upacara adat lempar lumpur yang dimiliki Dusun Sendang, salah satu dusun di Desa Sendang (hasil wawancara dengan K Muhroni, Nur Solikhin). Tradisi ini dilaksanakan pada bulan Agustus, tepatnya hari Jumat kliwon atau bulan September, disesuaikan dengan masa panen (hasil wawancara dengan Faizin). Popokan dilaksanakan setelah acara kirab, dimulai dari jam 15.00 WIB sampai dengan jam 15.30 WIB. Tradisi inipun awalnya hanya meliputi ritual popokan, perang lumpur di lokasi pesawahanan di Balai desa, Desa Sendang.

Selanjutnya tradisi dusun ini disepakati oleh warga Desa Sendang menjadi tradisi Desa Sendang. Ritual yang sebelumnya hanya popokan dimodifikasi dengan beberapa prosesi lainnya. Prosesi lainnya yang dilaksanakan bersamaan dengan popokan yaitu kirab hasil kreasi warga Desa Sendang. Kirab ini menampilkan hasil kreasi warga Desa Sendang, juga menampilkan kreasi lembaga-lembaga pendidikan dan kesenian warga Desa Sendang.

Dalam tradisi ini, warga Desa Sendang khususnya yang laki-laki dan yang masih muda saling melempar lumpur satu dengan yang lainnya, di persawahan Desa.
Dalam ritual lempar lumpur ini, setiap peserta ritual tidak diperkenankan marah atau emosi dikarenakan terkena lemparan lumpur dan peserta lainnya. Bahkan penonton yang melihat ritual ini juga tidak diperkenankan marah apabila terkena lemparan, dikarenakan orang yang terkena lemparan lumpur diyakini akan mendapat berkah. Semakin banyak lumpur yang mengenai badannya semakin banyak berkah yang akan diperolehnya.

Lokasi persawahan sebagai arena popokan dikondisikan oleh perangkat Desa, satu minggu sebelumnya. Lokasi dialiri dengan air secukupnya agar lahan persawahan berlumpur. Lumpur yang dipergunakan sebagai popokan merupakan lumpur yang lembek sehingga tidak menyakitkan apabila dipergunakan sebagai sarana untuk popokan (hasil wawancara dengan K Muhroni dan Nur Solikhin).

Tradisi popokan ini sudah berlangsung lama, turun temurun dari pendiri Desa Sendang sampai sekarang. Prosesi tradisi ini diawali dengan pembersihan mata air atau sendang, sesuai dengan nama Desa Sendang pada hari Kamis sore. Setelah shalat Jum'at, warga Desa membawa ambeng atau nasi yang dibentuk mirip gunungan dan jajan pasar ke rumah bayan (pengurus kampung) untuk acara selamatan. Setelah selesai acara ambengan, warga menuju perbatasan desa pertigaan Ntotog atau Dusun Ngasinan sebagai awal untuk mengadakan acara kirab atau arak-arakan dan selesai di Balai Desa Sendang. Dalam acara kirab ini disajikan kesenian dari Desa Sendang yaitu reog atau jatilan, noknik (pagelaran wayang orang), dan penampilan hasil kreasi warga di Desa Sendang. Di barisan depan dalam acara arak-arakan terdapat miniatur harimau. Di belakangnya diikuti oleh sekelompok rombongan yang berpakaian model adat. Miniatur harimau tersebut dilempar dengan lumpur, sebagai penghormatan kepada sesepuh Desa Sendang dulu yang berhasil mengusirnya dengan lumpur. Sampai di lokasi popokan, modin (pemuka agama) membacakan doa dan diikuti dengan 
perebutan nasi tumpeng oleh warga. Setelah pembacaan doa selesai, acara popokan dilaksanakan. Warga saling melempar lumpur di tengah persawahan, di perbatasan desa tanpa ada rasa emosi.

Dari perspektif historis, tradisi popokan, telah berlangsung sangat lama, konon telah berlangsung dari sesepuh Desa Sendang. Tradisi ini bermula dari munculnya seekor macan atau harimau yang merusak tanaman warga Desa Sendang dan mengancam warga desa. Warga Desa Sendang berusaha mengusirnya dengan berbagai senjata tajam, tetapi macan tersebut tidak mau pergi dari desa. Warga bertambah khawatir dan takut atas keberadaan macan tersebut. Selanjutnya ada sesepuh Desa Sendang yang menyarankan agar harimau itu jangan diusir dengan kekerasan dengan senjata tajam, tetapi usirlah dengan lumpur sawah. Benar saja, atas nasehat sesepuh desa tersebut, macan atau harimau itu akhirnya pergi dati Desa Sendang dengan cara melemparnya dengan lumpur sawah. Akhirnya lempar lumpur menjadi tradisi yang dilestarikan oleh warga Desa Sendang sampai sekarang ini.

\section{Ritual Popokan}

Popokan merupakan tradisi dari Dusun Sendang, Kelurahan Sendang Kabupaten Semarang. Tradisi popokan ini hakekatnya merupakan tradisi tasyakuran yang dilakukan oleh warga Desa Sendang atas keselamatan warga, panen yang melimpah yang diterima oleh seluruh warga desa. Tradisi popokan atau perang lumpur sebenarnya merupakan ending dari tradisi tasyakuran warga.

Secara garis besar, ritual popokan dapat diklasifikasikan menjadi empat macam. Pertama, bersih sendang atau sumber mata air di Dusun Sendang yang berjumlah empat sumber mata air, sendang Glagah, sendang Preh dan sendang Dawung. Bapak-bapak dan warga Dusun Sendang berpartisipasi aktif membersihkan mata air atau sendang yang ada di Dusun Sendang. Sebagian dan mereka membersihkan air sendang sampai bersih dari dedaunan ataupun endapan di dalamnya hingga air sendang terlihat jernih kembali. Sebagian yang lain membersihkan rumput liar atau pepohonan yang tumbuh di sekitar sendang dengan memangkasnya agar menjadi rapi. Sebagian membersihkan sekitar sendang dengan pacul sehingga tanah sekitar bersih terbebas dan rumput liar.

Bersih sendang atau sumber mata air ini dilakukan di sendang atau mata air yang berada di Dusun Sendang yang berjumlah empat sumber mata air yaitu sendang (kali) Preh, sendang Glagah, dan sendang Dawung (hasil wawancara dengan Nur Solikhin). Bersih sendang ini biasanya dilkuti oleh laki-laki dewasa dengan peralatan pacul, sabit, dan sapu. Sementara anak-anak usia sekolah tetap melakukan aktivitas kesehariannya sebagaimana biasanya. Mereka pergi ke sekolah dan tidak terlibat dalam tradisi bersih sendang ini. Sementara ibu-ibu menyiapkan makanan dan nasi tumpeng di rumah masing-masing.

Bersih sendang ini biasanya dilakukan pada hari Kamis sore, jam 13.00 sampai dengan jam 16.00 WIB, satu hari sebelum tradisi popokan dilakukan. Bersih sendang ini dilakukan oleh warga dikarenakan mereka berkeyakinan bahwa air merupakan sumber kehidupan, sumber kehidupan warga seluruhnya. Maka sumber kehidupan ini perlu untuk dibersihkan dari kotoran sehingga kehidupan merekapun akan bersih jauh dari kotoran ataupun marabahaya yang mengancamnya. Keyakinan inilah yang mendorong warga sangat antusias untuk membersihkan sendang yang ada di Dusun Sendang. Bersih sendang ini dilakukan dalam waktu satu tahun sekali bersamaan dengan tasyakuran desa atau popokan. Ada beberapa alasan yang mendasarinya.

Sendang bagi kehidupan masyarakat Dusun Sendang sangat vital. Setiap hari sebagian warga masyarakat menggunakan sendang sebagai tempat mandi, khususnya setelah pulang dan sawah. Di samping itu, 
sendang juga dipergunakan sebagai tempat untuk mencuci pakaian bagi ibu-ibu. Ibuibu biasanya mencuci pakaian anak-anak dan suaminya di sendang tersebut. Dengan demikian sendang mempunyai peran yang sangat vital bagi masyarakat Dusun Sendang.

Selanjutnya, dilakukan upacara tumpengan dari warga Dusun Sendang yang dibuat oleh setiap keluarga di dusun tersebut. Nasi tumpeng merupakan nasi yang dibuat dengan bentuk gunungan, dengan puncak yang lancip diletakkan di baskom, ataupun tampah (sejenis anyaman bambu yang diperuntukkan untuk nasi tumpeng). Nasi tumpeng itu dilengkapi dengan lauk pauk khusus. Lauk pauk sebagai pelengkap nasi tumpeng adalah klubanan, yaitu rebusan sayur mayur yang dicampur dengan sambal kelapa. Sambal yang terbuat dan lombok, garam, brambang dan bawang yang dicampur dengan parutan kelapa. Sayur mayur yang dibuat sebagai klubanan biasanya berasal dari bayam, kacang panjang, kluwih, sekarang biasanya daun kulbis, daun sawi, daun singkong, daun protoseli, daun kacang panjang dan dicampur dengan kecambah. Di samping itu, nasi tumpeng dilengkapi dengan ikan asin misalnya ikan ten, ikan pethek, atau dilengkapi dengan telur rebus, tahu tempe, daging ayam, ikan asin lainnya. Semua lauk pauk dan klubanan tersebut ditaruh melingkar di pinggir nasi tumpeng.

Nasi tumpeng juga dilengkapi dengan tuntuman. Tuntuman adalah sambal yang dicampur dengan parutan kelapa, biji mlanding, irisan jepan dan dibungkus dalam daun pisang kemudian dimasak sampai matang. Tuntuman ditaruh di sekitar nasi tumpeng sebagai tambahan jika klubanan dalam nasi tumpeng kurang.

Setiap keluarga di Dusun Sendang membuat nasi tumpeng yang akan dipergunakan sebagai bagian dan tradisi popokan. Di samping membuat nasi tumpeng warga juga membuat makanan kecil lainnya, seperti mereka menyiapkan lebaran. Bahkan warga yang di perantauan pun menyempatkan diri untuk pulang sekedar mengikuti tradisi popokan ini. Tradisi popokan ini secara emosional melebihi tradisi lebaran. Semua warga Desa Sendang seluruhnya tidak hanya Dusun Sendang, berpartisipasi aktif dalam tradisi ini, tanpa melihat agama yang dianutnya. Mayoritas warga Desa Sendang beragama Islam, tetapi ada sebagaian kecil warga di Dusun Sendang yang beragama Kristen. Semuanya menyatu dalam tradisi popokan ini.

Ritual tumpengan dilaksanakan di rumah modin (Imamuddin: pemuka agama). Warga Dusun Sendang khususnya bapakbapak datang membawa nasi tumpeng masing-masing ke rumah modin. Mereka duduk berjajar saling berhadapan, di tengahnya diletakkan nasi tumpeng yang dibawanya. Setelah seluruh warga Dusun Sendang datang dan berkumpul, acara tumpengan dimulai. Modin mulai membaca hadroh, ila hadharati ruhi, sampai lengkap ditanjutkan bacaan surat at Ikhlas, surat al Falaq, surat an Nas, dan bacaan sebagian ayat al Qur'an, tahlil sampai doanya. Doadoa dilakukan dalam versi Islam meskipun ada sebagian warga yang beragama Kristen. Setetah selesai berdoa, warga makan nasi tumpeng dan lauk pauk yang dibawanya secara bersamaan.

Awalnya ritual tumpengan hanya diikuti oleh warga Dusun Sendang (bukan Desa Sendang), tetapi pemerintah desa setempat mengelola tradisi ini sebagai pemberdayaan Desa Sendang, maka tumpengan pun diikuti oteh perangkat desa setempat dan tokoh-tokoh atau sesepuh Desa Sendang yang meliputi berbagai dusun.

Ketiga, kirab dan arak-arakan yang ditakukan oleh warga Desa Sendang seluruhnya. Arakan-arakan ini dilakukan mulai dari pertigaan Ntotog, persimpangan jalur ke Gubug dan jalur ke Kecamatan Bancak, Kabupaten Semarang sampai Balai Desa Sendang, sejauh kira-kira 2 kilometer. Kadang-kadang kirab dimulai dari Dusun Ngasinan, dusun paling barat dilanjutkan sampai balai Desa Sendang (hasil wawancara dengan Nur Solikhin). Arak- 
arakan ini diikuti oleh warga Desa Sendang, anak-anak, pemuda dan orang tua. Dalam arak-arakan ini, warga menampilkan seni dan seluruh kreatifitasnya. Setiap dusun di Desa Sendang menampilkan kreatifitasnya masing-masing bahkan setiap RT di setiap dusun mempunyai kreatifitasnya masingmasing.

Dalam arak-arakan atau kirab itu, warga melakukan ritual dengan mengarak atau menggiring hewan macan yang terbuat dan boneka, yang di dalamnya berisikan orang. Di samping itu, warga juga mengarak nasi tumpeng yang dilengkapi dengan ingkung, ingkung burung dara, ikan wader, udang, ikan belut hasil tangkapan dan warga. Burung dara, ikan wader, udang, dan belut. Kesemuanya merupakan hasil tangkapan dan warga, bukan hasil ternak dan bukan beli dari pasar. Setelah sampai balai desa, Desa Sendang, modin atau kiai membaca doa atas nasi tumpeng yang dibawa di belakang kirab miniatur harimau. Setelah itu, dilanjutkan dengan berebut nasi tumpeng dan ayam panggang yang dibawa oleh para sesepuh masyarakat sekitar (hasil wawancara dengan Nur Solikhin).

Arak-arakan ini dilakukan pada hari Jum'at kliwon, setelah melaksanakan ibadah shalat Jum'at. Arak-arakan ini dilakukan dari jam 13.00 sampai jam 15.00 WIB, sehingga jalan raya antara SalatigaBancak praktis macet selama tiga jam ataupun kalau jalan, hanya satu jalur. Jalur mobil yang melewati jalan ini ditutup sementara waktu sampai tradisi popokan selesai, sekitar jam 16.00 WIB.

Menurut Ulis Sa'adah, jalur lalu lintas untuk sepeda montor dapat dialihkan lewat jalur sebelah selatan, bersamaan dengan tradisi popokan dilaksanakan. Jalur selatan yang melewati Desa Lebak di selatan, Desa Sendang. Sementara mobil roda empat tetap melewati jalur Salatiga Bancak tidak dialihkan ke jalur lain.

Keempat, popokan atau perang lumpur berlangsung di dekat Balai Desa Sendang, di jalan Raya Salatiga-Bancak. Tradisi lempar lumpur antar warga berlangsung sangat meriah, dikarenakan diikuti oleh anak anak, remaja dan orang tua khususnya yang laki-laki. Mereka tampak asyik saling melempar tanpa sasaran yang jelas. Bahkan kadang terjadi aksi saling kejar mengejar untuk saling melempar di area persawahan yang dipergunakan sebagai ajang perang lumpur. Menurut Faizin (mantan kepala Desa Sendang), peserta perang lumpur tidak diperkenankan marah dan emosi karena terkena lemparan lumpur dari peserta lain. Sebaliknya, warga yang terkena lemparan lumpur ini akan merasa senang, karena dipercaya akan dapat berkah.

Sementara itu, mobil-mobil dihentikan sementara di Dusun Pondok yang berasal dari jalur timur, dan yang berasal dari jalur barat dihentikan di Dusun Ngasinan untuk ,emghindari terkena lemparan lumpur dari peserta popokan, demikian diungkapkan Heru dan Ulis Sa'adah.

Aksi lempar lumpur ini dilakukan di jalan raya antar desa yang berada di area persawahan Desa Sendang, Kabupaten Semarang. Tradisi perang lumpur ini tetap dilakukan oleh warga, untuk menghormati warisan budaya nenek moyang mereka. Upacara popokan ini bermakna sebagai bentuk rasa syukur warga kepada leluhur yang telah berhasil mengusir hewan buas yang mengganggu warga.

Tradisi perang lumpur atau yang biasa disebut popokan merupakan tradisi pengusiran binatang buas seperti harimau dan macan di sekitar pemukiman warga karena sering merusak area persawahan. Kegiatan ini dilakukan nenek moyang mereka jaman dahulu.

Tradisi popokan merupakan manifestasi atas keselamatan warga dari berbagai ancaman manabahaya dan manifestasi hasil bumi yang melimpah. Tradisi ini khususnya merupakan wujud rasa syukur masyarakat petani Desa Sendang kepada Tuhan Yang Maha Esa atas hasil panen yang diperolehnya dan memohon berkah keselamatan bagi masyarakat setempat khususnya para petani. 
Dengan demikian popokan bermakna pembersihan din atau menghilangkan kejahatan dengan cara yang santun tanpa kekerasan, dengan rendah hati dan taat pada Allah swt.

\section{Alasan Tradisi Popokan}

Tradisi popokan merupakan warisan dan nenek moyang mereka yang telah berlangsung cukup lama. Menurut Faizin, popokan merupakan ritual pengusiran terhadap macan yang masuk dan mengganggu warga Desa Sendang. Cerita tentang pengusiran terhadap binatang menurut Faizin hanya berlangsung sampai pada Mbah Darmo, sesepuh nonik yang berasal dan Kayuglagah, Beji, Kecamatan Tuntang, Kabupaten Semarang.

Menurut Nur Solikhin cerita tentang pengusiran harimau yang mengganggu warga terjadi pada masa mbah Semendi (sesepuh Desa Sendang). Beliau adalah sesepuh Desa Sendang yang berasal dari Yogyakarta, yang dalam pengembaraannya beliau menetap di Dusun Sendang. Dusun yang banyak sendangnya atau sumber mata air cocok untuk bermukim.

Menurut Faizin, alasan yang melatarbelakangi tradisi popokan tetap dilestarikan di Desa Sendang ada tiga hal. Pertama, tradisi ini dianggap sebagai upaya untuk melestarikan budaya lokal sebagai warisan dari nenek moyang mereka. Tradisi popokan sebagaimana asal muasalnya yang merupakan upaya sesepuh desa zaman itu untuk mengusir macan yang mengganggu warga Desa Sendang.

Popokan yang dimaknai sebagai upaya mengusir harimau yang mengganggu warga desa dengan cara melempar lumpur sawah. Melempar lumpur pun tetap dilestarikan sampai sekarang ini. Di samping popokan sebagai tradisi yang perlu dilestarikan dan dijaga oleh warga Desa Sendang, ada pula tradisi lain sebagai tahapan popokan. Tradisi lain itu adalah membersihkan sendang atau mata air di Desa Sendang.

Kedua, tradisi popokan mengangkat dan mengenalkan tradisi lokal ke tingkat nasional. Tradisi popokan awalnya hanya dikenal di Desa Sendang, Kecamatan Bringin, Kabupaten Semarang. Seiring dengan perubahan zaman dan perkembangan teknologi yang begitu cepat tradisi popokan tidak hanya dikenal di wilayah Kecamatan Bringin saja, tetapi juga dikenal di Jawa Tengah.

Upaya untuk mengangkat dan memperkenalkan tradisi popokan ke tingkat nasional dikemas dengan berbagai acara tambahan yang dapat menyedot perhatian warga. Acara kirab dan arak-arakan yang melibatkan massa yang banyak merupakan salah satu upaya untuk memaksimalkan tradisi popokan. Kirab ini melibatkan berbagai kelompok seni yang ada di masyarakat Desa Sendang, misalnya nonik, wayang orang, drum blek, kelompok drumband yang berasal dan kaleng bekas, jatilan. Di samping kelonipok seni, kirab atau arak-arakan ini juga melibatkan semua kelompok lembaga pendidikan dan Raudlatul Atfal (RA) sampai Sekolah Dasar (SD) yang ada di Desa Sendang, termasuk lembaga pendidikan dan Madrasah Diniyah (Madin), Taman Pendidikan Al Qur'an (TPQ) yang ada di Desa Sendang. Dalam kirab tersebut juga ditampilkan karya dan hasil kreatifitas warga Desa Sendang misalnya modifikasi teknologi, pesawat, kapal dan lainnya, hasil pertanian warga di Desa Sendang.

Dengan demikian kirab ini melibatkan massa yang cukup banyak tidak hanya dan masyarakat Desa Sendang dan Kecamatan Bringin tetapi juga masyarakat luar. Hal ini dibuktikan dengan beberapa kali stasiun TV nasional melakukan liputan acara popokan ini misalnya ANTV atau Indosiar. Penonton berjajar dari kanan kiri pertigaan Ntotog sampai balai desa, Desa Sendang. Mereka datang dari kota-kota lain, sperti Purwodadi, Gubug, Demak, Kudus, Pati, Salatiga, dan Semarang kota. Mereka datang karena penasaran dengan tradisi lempar lumpur atau popokan yang dilakukan oleh warga Desa Sendang. Setelah mereka melihat secara langsung tradisi ini mereka percaya bahwa ada tradisi 
lempar lumpur di Desa Sendang ini. Tradisi ini dilestarikan oleh warga sebagai bentuk rasa syukur terhadap Allah swt atas terjauhnya dari berbagai bahaya yang mengancam warga baik fisik maupun non fisik. Tradisi popokan sebenarnya berasal dari tradisi Dusun Sendang saja. Untuk mengangkat tradisi lokal ini, pemerintah Desa Sendang bekerjasama dengan Dinas Pariwisata Kabupaten Semarang memberdayakan tradisi popokan menjadi tradisi yang layak untuk dilihat dan ditonton sebagai salah satu wisata tahunan bagi warga Kabupaten Semarang.

Ketiga, tradisi popokan dikembangkan dan dimodifikasi menjadi beberapa prosesi yang bersifat massal. Tradisi dikembangkan dengan kirab dan arak-arakan yang melibatkan sejumlah elemen masyarakat. Diupayakan tradisi ini tidak hanya milik warga Desa Sendang atau kecamatan Bringin, tetapi menjadi milik warga Kabupaten Semarang.

Pemerintah desa, Desa Sendang dalam memodifikasi tradisi popokan melibatkan pemerintah Kabupaten Semarang, khususnya Dinas Pariwisata. Dalam acara popokan, mulai dari prosesi kirab atau arak-arakan, Bupati Semarang, menyempatkan hadir untuk membuka acara kirab dalam acara popokan ini didampingi Kapolres Kabupaten Semarang dan Camat Bringin. Dengan kehadiran beberapa pejabat Kabupaten Semarang menjadikan acara popokan ini semakin meriah, sekaligus menjadi salah satu obyek wisata di Kabupaten Semarang, khususnya Kecamatan Bringin. Dengan demikian tradisi popokan menjadi salah satu kebanggan Kabupaten Semarang sebagai tradisi yang unik.

Dengan demikian tradisi popokan membutuhkan biaya yang cukup besar yang menjadi beban warga Desa Sendang, bukan hanya Dusun Sendang. Biaya yang besar biasanya dipergunakan untuk konsumsi bagi peserta kirab atau arak-arakan, serta untuk honor kelompok seni yang berpartisipasi dalam acara kirab tersebut. Dengan partisipasi warga Desa Sendang, maka biaya yang cukup besar dapat diselesaikan. Dana yang besar dibebankan kepada seluruh warga Desa Sendang, sehingga seluruh warga dilibatkan dalam tradisi popokan ini. Demikian hasil wawancara penulis dengan mbah $\mathrm{K}$. Muhroni, tokoh agama dari Dusun Ngasinan.

\section{Makna Tradisi Popokan}

Makna simbol dari piranti tradisi popokan di Desa Sendang, Kecamatan Bringin, Kab. Semarang berupa:

\section{Tumpengan}

Masyarakat Jawa mempunyai variasi budaya yang beraneka ragam. Nasi tumpeng merupakan salah satu budaya Jawa. Tumpeng merupakan sajian dengan bahan utama nasi yang dibuat berbentuk kerucut menyerupai bentuk gunung. Di bawahnya ditata berbagai jenis lauk pauk khusunya klubanan dan berbagai macam hiasan agar kelihatan menarik. Nasi tumpeng kuning melambangkan kesejahteraan, kekayaan, atau rejeki yang melimpah. Nasi tumpeng kuning pada bagian bawahnya terdapat lauk-pauk, seperti sayuran dan olahan berbagai jenis daging.

Nasi tumpeng yang dibuat kerucut pada puncaknya mempunyai makna bahwa tujuan dan semua mahluk hidup di dunia itu adalah Allah swt sebagai pencipta, Tuhan penguasa alam semesta. Kemudian manusia berada di bawahnya. Sedangkan pada bagian paling bawah terdapat berbagai jenis lauk pauk, apakah yang terbuat dari jenis daging atau ikan dan berbagai macam sayuran. Ini melambangkan kehidupan tumbuhan dan hewan yang berada di bawah manusia. Nasi tumpeng yang dibuat sedemikian rupa melambangkan keharmonisan kehidupan manusia. Hubungan manusia dengan Tuhan, manusia dengan hewan dan tumbuhan, maupuan hubungan yang harmonis antara manusia itu sendiri.

Secara umum nasi tumpeng mempunyai makna sebagai ungkapan puji syukur kepada Allah atas atas limpahan rejeki yang telah Dia berikan. Juga disertai 
harapan agar seluruh manusia akan selalu hidup tenteram, sehat dan sejahtera di masa yang akan datang. Dalam bahasa Jawa kata selamatan dikenal dengan slametan, yang merupakan salah satu kegiatan yang cukup penting dalam setiap upacara ritual yang diadakan. Slametan dan kata slamet yang artinya terhindar dari suatu kejadian yang tidak diinginkan secara lahiriah dan batiniah serta selalu dalam pengayoman dan Ilahi Rabbi, Gusti Kang Murbeng Dumadi.

Filosofis makna slametan dalam bahasa Jawa dinyatakan dengan ungkapan bahwa manungsa iku urip ing alam donya ora mung luru pangan, sandhang lan papan ananging uga luru kasuwargan. Dalam setiap kegiatan kehidupan orang Jawa yang belum ilang jawane memulai sesuatu usaha dalam kesehariannya selalu didahului dengan slametan, sejak seseorang dilahirkan, menjalani kehidupannya, sampai masuk kembali ke liang kubur, selalu disertai dengan acara slametan. Slametan juga dilakukan ketika dalam kandungan empat bulan, tujuh bulan, sampai kelahiran, dilanjutkan slametan ketika khitan, menikah dan seterusnya. Dengan menyadari kelemahan dan kekurangan pada dirinya dan keyakinannya yang bulat akan adanya Allah, maka setiap gerak langkah orang Jawa selalu dimulai dengan memohon kepada Allah dalam bentuk slametan. Dalam slametan disertai permohonan (panuwunan) akan kebaikan semuanya yang terekspresi dalam nasi tumpeng.

Tumpeng, mempunyai arti dan maksud tumuju lempeng marang Gusti atau tertuju kepada Allah swt, juga dapat diartikan dedonga anteng, meneng, Jejeg, menthentheng, yang artinya berdoa itu dengan tenang, khusuk, istiqamah dan fokus. Bentuk tumpeng yang bulat kerucut berbentuk seperti gunung dan terbuat dan nasi putih adalah mengandung arti "dalam memohon kepada Tuhan hendaknya disertai dengan fiat dan jiwa yang bersih (seperti warna tumpeng) tenang dan teguh atau kokoh seperti gunung”.

Cara memotong tumpengpun tidak boleh sembarangan asal memotong, karena memotong dengan sembarangan dapat menghilangkan esensinya. Diawali tumpeng dipotong ujungnya yang memiliki arti sebagai pancer, dan potongan yang satunya dipotong atau dibelah secara melintang yang sehingga terbagi menjadi 4 bagian yang memiliki anti sebagai sedulur kembar papal atau empat unsur alam yang mempengaruhi sifat manusia. Potongan yang melambangkan pancer tadi tidak untuk dimakan, tetapi dilengkapi dengan lauk pauk tumpeng dan dipersembahkan kepada Gusti Maha Agung. Sedangkan potongan tumpeng yang terbelah menjadi empat bagian itulah yang dimakan beramairamai dan ini memiliki arti atau harapan agar 4 unsur alam yang ada dalam diri manusia tetap dapat memberikan pengaruh yang baik pada diri manusia, empat unsur alam itu adalah "air, api, udara dan tanah". Sifat-sifat alam mi harus ada dalam diri manusia karena apabila sifat alam ini tidak ada dalam diri manusia maka ia seperti orang mati.

Dalam prosesi tumpeng ada proses islamisasi dan modifikasi sehingga sesuai dengan ajaran Islam. Islam sangat menganjurkan untuk memanfaatkan sesuatu semaksimal mungkin, menghindari perilaku mubadzir. Dengan demikian semua nasi tumpeng dapat dimakan untuk menghindari perilaku mubadzir.

\section{Nasi Klubanan}

Klubanan dan lauk pauk dalam tumpeng memiliki makna yaitu variasi dan berbagai macam rasa dalam kehidupan, layaknya seperti rasa klubanan, ada rasa pedas, rasa asin, rasa sepet, rasa asam. Kombinasi berbagai rasa ini akan memberi kenikmatan hidup yang bisa membuat hidup semakin berkualitas.

Dalam klubanan biasanya ada daun bayem yang artinya dapat membuat adem ayem, kacang panjang yang maknanya yuswa dawa, kecambah yang maknanya tansah sumrambah, kluwih yang maknanya luwih-luwih, kangkung yang maknanya jinangkungan dening Gusti Kang Murbeng Dumadi atau selalu mendapat perlindungan 
dan Allah. Klubanan tersebut apabila dirangkai adalah wong urip yen tansah ayem tentrem, bakale yuswane dawa lan tansah sumrambah lan bisa luwih-luwih, apa-apa tansah jinangkungan dening Gusti. Artinya, apabila dalam menjalani hidup ini dengan tenang dan tentram, maka umur akan panjang, selalu berkembang serta mendapat kecukupan, dan semua yang dijalankan selalu mendapatkan perlindungan dan Ilahi Rabb, Tuhan Yang Maha Esa.

\section{Ingkung}

Nasi tumpeng mempunyai makna khusus, demikian dengan klubanan sebagai pelengkapnya. Ingkung merupakan kelanjutan dan makna nasi tumpengan dan klubanan tersebut. lngkung mempunyai makna filosofis yaitu kembali kepada kesucian, atau kembali kepada fitrah. Fitrah atau kesucian akan tercapai dan terwujud, apabila seseorang tersebut telah menjalani dengan tetap menjaga hubungan dengan Ilahi Rabb, menjaga hubungan dengan sesama dan menjaga hubungan dengan makhluk yang lain.

Ingkung hakekatnya memiliki makna kesucian dan fitrah, seperti ayam ingkung yang nglegeno atau telanjang tanpa bulu. Dan ini adalah tujuan akhir dari hidup, yaitu mancapai kesucian. Maka tujuan hidup pada dasarnya adalah untuk mencapai kesucian, fitrah sebagai tujuan akhir. Tujuan yang akan dicapai oleh setiap insan adalah untuk mencapai kesucian, fitrah setelah menjalani kehidupan dengan rasa serasi dan harmonis.

Dengan demikian bahwa tradisi popokan mempunyai beberapa makna. Pertama, tradisi popokan merupakan ungkapan untuk menerima realitas kehidupan apa adanya dengan berbagai rasa kehidupan. Warga Desa Sendang akan menerima kehidupan ini dengan dengan nerimo setelah melakukan ikhtiar yang maksimal. Mereka akan mengolah lahan pertanian mereka dengan sebaik-baiknya atau akan bekerja sesuai dengan profesinya. Ketika tiba waktunya panen, bersamaan dengan bulan Agustus, warga akan menyelenggarakan tradisi popokan, sebagai ungkapan menerima atas segala ketentuan yang mereka terima.

Kedua, tradisi popokan merupakan ungkapan rasa syukur kepada Allah swt atas limpahan kenikmatan, keberkahan dalam kehidupan ini. Warga Desa Sendang mengungkapkan rasa syukur kepada Allah swt setelah menerima berbagai kenikmatan utamanya panen yang mereka terima. Bentuk syukur itu mereka ekspresikan melalui berbagai prosesi dalam tradisi popokan, mulai dan bersih sendang, kirab warga, nasi tumpeng dan popokan. Demikian pula, mereka bersyukur terjauhkan dari berbagai marabahaya yang mengancamnya. Dulu moyang mereka terancam harimau yang masuk ke wilayah desanya, sekarang ancaman dan marabahaya dapat terwujud dalam bentuk narkoba, minuman keras, dan perilaku jelek lainnya.

Ketiga, tradisi popokan merupakan ekspresi rasa, seni, kreatifitas hidup dan kehidupan warga Desa Sendang khususnya. Ekspresi ini diwujudkan dalam bentuk kirab sebelum acara popokan. Kirab melibatkan berbagai kelompok seni, misalnya kelompok nonik, kuda lumping, drumblek, sehingga mereka dapat mengekpresikan kemampuan seni. Di samping itu, semua kelompok warga dapat menampilkan hasil kreatifitasnya dan hasil pertanian yang mereka miliki.

\section{Simpulan}

Awalnya tradisi popokan merupakan tradisi asli Dusun Sendang, berkembang menjadi tradisi Desa Sendang. Selanjutnya berkembang menjadi tradisi unik di Kabupaten Semarang setelah Dinas Pariwisata Kabupaten Semarang mengelolanya.

Tradisi popokan tidak sebatas tradisi perang lumpur antar warga Desa Sendang, tetapi dimodifikasi dengan berbagai prosesi, dimulai dari bersih sendang atau sumber air, tumpengan, kirab dan popokan. 
Tradisi popokan merupakan ungkapan syukur kepada Allah sebagai penguasa jagat raya, terjauhkan dari berbagai bencana dan musibah, bertambahnya berbagai kenikmatan. Tradisi popokan juga sebagai ekspresi kemampuan seni dan kreatifitas mereka, terlebih setelah Dinas Pariwisata Kabupaten Semarang mengelolanya. Tradisi popokan merupakan upaya untuk menjaga kearifan lokal, tradisi nenek moyang yang perlu dilestarikan, dengan sebaik-baiknya.

\section{Daftar Wawancara dan Informasi}

Dokumen Desa Sendang, Kecamatan Bringin, Kabupaten Semarang.

Wawancara dengan Nur Faizin, tanggal 10 Juli 2016, jam 11.00 sampai dengan 13.00 .

Wawancara dengan Nur Faizin, tanggal 24 Juli 2016, jam 13.00 sampai dengan 15.15 .

Wawancara dengan Nur Faizin, tanggal 27 Juli 2016, jam 11.00 sampai dengan 12.00 .

Wawancara dengan Nur Solikhin, tanggal 27 Juli 2016, jam 10.00 sampai dengan 11.45 .

Wawancara dengan Kiai Muhroni, tanggal 27 Juli 2016, jam 13.15 sampai dengan 14.35.

Wawancara dengan Heru Saputro, tanggal 28 Juli 2016, jam 07.30 sampai dengan 08.00.

Wawancara dengan Ulis Sa'adah, tanggal 28 Juli 2016, jam 13.00 sampal dengan 13.20 . 